\title{
The Death Sentence of Doctor Apathy and Mental Illness
}

\author{
Andrea Brooks* \\ Department of Nursing, University of Houston, USA
}

*Corresponding author: Andrea Brooks, Department of Nursing, University of Houston, USA.

Received Date: October 09, 2019

Published Date: October 18, 2019

Keywords: Mental illness; Schizophrenia

\section{Opinion}

This piece is a true account of the author's loss of her father last month, a paranoid schizophrenic. Mental illness affects many people in various ways. Mental wellness is always in a delicate balance with the likelihood that at any moment a variable in life may shift this mental wellness into mental illness. This can occur in the same manner as one's physical, social, or even spiritual health. If a shift in one's physical health occurs, the person is given diligent, ethical, and effective care from healthcare professionals. What if this same person had not only a physical health shift, but also had a diagnosis of paranoid schizophrenia? In theory, the care should be no different. After all, healthcare professionals are taught not to judge and not to care for a mentally ill person any differently than someone without mental illness. However, the author saw it unfold differently. In reality, however, a paranoid schizophrenic diagnosis changes the conversation dramatically. No longer would the patient be addressed directly but his daughter would be addressed instead. She was the doctor and was well respected, while her father...was mentally ill. He would often protest, asking that they speak to him! He wanted to be involved in his own care but was only addressed when he protested.

Before his daughter the doctor came into the picture, the paranoid schizophrenic tried to obtain treatment on his own. He experienced severe weight loss of over 40 pounds within a year, along with bloody stools, abdominal pain, difficulty walking, and decreased appetite. One would expect health care providers would look at the big picture and evaluate for cancer. The fact is, the paranoid schizophrenic did not want to trouble his daughter.
He tried to obtain an answer on his own for a year before bringing it to her full attention. During this time, doctors referred him to a nutritionist and told him "good job" on the weight loss. His primary care provider laughed when he explained that there was blood in his stools and told him, "You must have eaten too many beets". She dismissed him when he returned to the clinic repeatedly until he became frustrated and changed primary care providers. His CT scans showed suspicious hepatic lesions indicative of cancer metastasis. He was instructed to follow up with his new primary care provider who told him, "You are fine". He finally gave up and ceased his psychotic medications. He wanted a clear mind because he knew deep inside that something was wrong. He finally asked his daughter, the author, for help.

When he changed hospital systems and insurances, he was diagnosed with stage four rectal neuroendocrine carcinoma with metastasis to his liver, lungs, and spine. He also had a large tumor almost obliterating his rectum. At this time of diagnosis, he was given no longer than a year to live, and he died after six months. When his daughter asked his primary care doctor why his CT scans were not evaluated further, she was told, in front of her father, "Well, you know how it is. He is mentally ill, so I never took him seriously". It was if someone took the author's life and view of medicine, her own view of mental illness, and her father away from her in a signal moment. This account is intended to provide a true account of how dismissing someone due to mental illness can cause an untimely death. What happens in one's mind when he or she sees the diagnosis of paranoid schizophrenic in a chart? Is it fear 
or anxiety of what the patient may do? Is it the desire to quickly diagnose and treat so that the patient will leave? The author admits that a mental illness diagnosis places her on a level of alert, but due to personal experience with her father she would not immediately dismiss the patient's concerns due to this diagnosis.

The author's fear is of a systemic underlying belief that a person with mental illness is simply a burden to society. However, the author's father, the paranoid schizophrenic, was not a burden. He was a father to two beautiful daughters who he encouraged and indulged. A father who never judged and always made time to talk. He was a grandfather to three granddaughters, the youngest of whom is eleven years old and will miss her yearly Easter egg painting and art talks with her grandfather. She will miss honoring him at her school every Veteran's Day with a smiling picture, proud of her grandfather who served in the Army as a chaplain's assistant. He was a loving husband to his wife of 43 years. All of these were the relationships that he was able to maintain despite his diagnosis, and they are no more due to his untimely death. A mental illness is another piece of a patient's puzzle to consider when giving care and should not be used as a deterrent or a fear factor that determines treatment. Like other traits such as race or sexual orientation, mental illness should not determine the quality or type of care.

\section{Acknowledgement}

My father Donald C Bishop and my editor Christina Ginn, M. Ed.

\section{Conflict of Interest}

No Conflict of Interest. 